Military Technical College

Cairo, Egypt

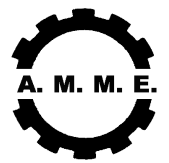

$12^{\text {th }}$ International Conference on Applied Mechanics and Mechanical Engineering (AMME)

\title{
EFFECT OF PIPE INCLINATION AND ADDING FINES ON SLURRY TRANSPORT OF COARSE PARTICLES
}

\author{
Fangary, Y.S.* and Mahmoud, N.A. *
}

\section{ABSTRACT}

This work presents results for slurry transport systems which combines the effect of adding fines to the carrier and varying pipe inclination angle. Results showed that adding fines sometimes reduces pressure head-loss when the pipes starts to incline upward. The deposit velocity increases with pipe inclination till $30^{\circ}$ and then decreases. The deposit velocity was found to vary remarkably when fine particles are added to the carrier fluid.

\section{KEYWORDS}

Slurry, pipelines, rheology, Two-phase, deposit velocity.

\footnotetext{
* Assistant professor, Mechanical Power Department, Faculty of Engineering, Ain Shams University, Cairo, Egypt. (Corresponding author, e.mail: ys fangary@yahoo.com)

** Professor, Mechanical Power Department, Faculty of Engineering, Ain Shams University, Cairo, Egypt.
} 


\section{INTRODUCTION}

Basically slurry transport by pipes has drawn special attention of mining industry. This was in order to transport mine waste and for dredging operations. Research work was carried out to provide methods for predicting pressure head loss in a system for specific application.

For many years slurry transport using pipes was restricted to relatively short distances for low concentrations and high velocities were employed in order to prevent blockage of pipes. Long distance slurry transport was the focus of many research projects which started studying the use of dense carrier to make long distance transport possible. It must be born in mind that during transport of solids over long distances, the pipeline may incline up or down at various angles depending on the terrain. Therefore, the effect of pipeline inclination on the slurry transport parameters should be also studied.

Before discussing the experimental work carried out in this study, it will be helpful to review previous work regards the subject.

\section{REVIEW}

\section{Effect of adding fines on slurry transport}

The transport of coarse sand particles in clay-water mixture was studied by Charles and Charles [1] and they found that a reduction in pressure drop by a factor of 1.67 compared to that when sand was transported using clear water was observed. This was contradicted by the findings of Kenchigton [2] who reported that the transport of sand with various concentrations in $40 \%$ by weight clay-water mixture gave higher pressure drop than the transport of sand in clear water. This was explained as the dense carrier has higher friction factor than that of clear carrier.

Duckworth et al [3] focused on the importance of rheology of the carrier fluid on the transport process. They suggested that in order fines addition to be effective the fines slurry should behave as Bingham fluid having yield stress. Their results showed that adding coarse particles to the slurry of fines gave the same behavior as the fines slurry. Further work was carried out by Duckworth et al [4] to examine the effect of varying the concentration of fines on the yield stress and plastic viscosity of the fines slurry. The results showed that the relation between the fines concentration and the yield stress of the fines slurry is of the power type. The same hold for the plastic viscosity.

In order to formulate the relation between the pressure head-loss and flow velocity when the carrier fluid contains fine particles, Duckworth et al [5] presented a set of design equations which can be used under laminar flow conditions.

Hou [6] carried out an analytical study to identify the conditions required to form and sustain high concentration slurry. He suggested that a slurry containing a given amount of fines will support large particles, only, if a continuous particle size distribution exists. Therefore a rational selection of particle size distribution leads to a direct increase of transport efficiency.

Sellgren and Addie [7] discussed the transport of coarse sand particles when adding fines to the carrier. They used clay or fine sand as the fine material. Results showed that preparing fine slurry using sand gives higher reduction in pressure head-loss which indicates that the type of fine material is important in transport processes. The effect of size distribution was also studied and the results showed that sand with the broadest size distribution gave reduced head loss by about $50 \%$ with other sands of 
narrow size distribution. Fangary et al [8] showed that using fine phosphate slurry reduces the transport of coarse phosphate particles remarkably than using clear water as the transport carrier, but their experiments were restricted to low solids concentration $\approx 4 \%$ by weight.

Ghanta and Purohit [9] carried out experiments using two materials; coal and copper ore. For both materials bi-dispersed mixture gave lower head loss than either fines or coarse. For coal, hydraulic transport of fine particles gave higher head losses than that of coarse particles for the same concentration. The opposite trend was observed for copper ore. This shows that the rheology of the fines slurry plays an important role in the hydraulic transport of solids.

\section{Effect of pipe inclination on slurry transport}

Kawashima and Noda [10] carried out experiments in order to determine the effect of pipe inclination on pressure head loss during transportation of slurries in such pipelines. They reported comparison between pressure head loss and flow velocities at two angles only; zero and $60^{\circ}$. It was found that increasing pipe inclination increases the pressure head loss for all flow velocities. Further studies were carried out to determine the effect of pipe inclination on slurry deposit velocity. Hashimoto et al [11] carried out experiments to verify the effect of inclination angle, particle size and solids concentration on deposit velocity. The results showed that increasing pipe inclination up to $30^{\circ}$ and increasing solids concentration increased deposit velocity. Also when decreasing particle size the deposit velocity increases. Wilson and Tse 12 extended the work first done by Hashimoto et al [11] and varied pipe inclination up to $40^{\circ}$. They found that increasing pipe inclination increases settling velocity to a peak at approximately $30^{\circ}$ then by further increasing pipe inclination the deposit velocity decreases.

From previous studies we find that the study of the effect of pipe inclination and adding fines to the slurry were studied separately. Therefore the main objective of this work is to find the effect of both variables simultaneously on slurry transport processes.

\section{EXPERIMENTAL WORK}

Experiments were carried out using the hydraulic transport test rig shown in Fig.1.The test rig is of the closed loop type. It comprises of a mixing tank of volume 1 $\mathrm{m}^{3}$, where solid-liquid mixing takes place. The mixture is agitated by means of a 4 blade pitched impeller $45^{\circ}$ pumping upwards. The mixture is forced to flow in the loop by a slurry pump of maximum power $15 \mathrm{HP}$. The mixture flows in steel pipe circuit of total length $20 \mathrm{~m}$ and pipe inner diameter $0.0508 \mathrm{~m}$. A Perspex section is fitted in the piping system, as shown in Fig.1, to allow for deposit observation and corresponding velocity was measured using measuring tank. The pipes were constructed in such a way that two parallel pipes can incline together. In case the feed pipe is having positive inclination, the return pipe will have negative inclination with the same value. Inclination angle may be varied from horizontal up to $45^{\circ}$. Pressure head-loss was measured over a pipe length of $4 \mathrm{~m}$ using differential manometers. After passing through the pipes, the slurry may either return to a measuring tank for flow and concentration measurements or to the mixing tank again. 
Experiments were carried out using coarse phosphate of $d_{50}=0.275 \mathrm{~mm}$ and density $2680 \mathrm{~kg} / \mathrm{m}^{3}$. Fine phosphate particles have $d_{50}<75 \mathrm{~m}$ and density 2690 $\mathrm{kg} / \mathrm{m}^{3}$.

\section{RESULTS AND DISCUSSION}

Experimental work was carried out in order to determine the effect of adding fine particles on the hydraulic transport of solids in inclined pipes.

Fig.2 shows the effect of inclination angle on pressure head loss of coarse phosphate with weight concentration $10 \%$. From this figure we find that there is no slight effect of inclination angle on pressure head loss. Fig.3 shows the effect of inclination angle on pressure head loss of fine phosphate slurry with the same concentration i.e. $10 \%$. The figure shows that increasing the angle of inclination increases the pressure head loss at the same flow velocity.

Increasing the coarse solids concentration to $15 \%$ by weight shows that the inclination angle affects remarkably the pressure head loss as shown in Fig.4.From this figure it can be seen that increasing the inclination angle increases the pressure head loss at the same flow velocity without convergence of the lines of pressure head loss at high velocities. For fine phosphate slurry with concentration $15 \%$ by weight similar results were obtained, shown in Fig.5. Comparing results shown in Figs 2, 3, 4 and 5 we find that increasing solids concentration (coarse or fine) increase the pressure head loss at the same flow velocity. Also coarse particles slurry gave higher pressure head loss than fine particles slurry flowing at the same velocity. Increasing the solids concentration increases the difference in values of pressure head loss between coarse and fine particles.

On varying the percentage of fine particles in a mixture of fine and coarse particles varies the pressure head loss. Fig. 6 shows the effect of varying the percentage of fine particles in phosphate slurry with total (coarse + fine) concentration of $10 \%$ flowing in horizontal pipe line. From this figure we notice that increasing the percentage of fine particles decreases remarkably the pressure head loss compared to coarse particles. The mixture of $33 \%$ coarse gave pressure head loss even lower than the pressure head loss of $100 \%$ fine slurry. Increasing the angle of inclination to $20^{\circ}$ upward, Fig. 7 shows that the lines of pressure head loss starts to converge and that the effect of adding fines changes the behavior of the slurry. From this figure we find that slurry containing fines with $50 \%$ gave the higher pressure head loss. Further increase of inclination angle to $40^{\circ}$ shows that results obtained from Fig.7 still holds as shown in Fig.8. Thus we conclude that varying the angle of inclination affects the flow behavior of slurries containing fine particles.

Fig.9 shows the effect of adding fines on pressure head loss of phosphate slurry in horizontal pipe with weight concentration of $15 \%$. From this figure we find that increasing the fines percentage to $25 \%$ increases the pressure head loss compared to coarse particles at flow velocities $<3 \mathrm{~m} / \mathrm{s}$. Further increase of fine particles concentration decreases the pressure head loss compared to coarse particles and minimum pressure head loss is obtained at $50 \%$ fine particles. Increasing the inclination angle to $20^{\circ}$, Fig.10, gave the same results as in Fig.9. but the pressure head loss values are shifted towards higher values. Further increase of inclination angle to $40^{\circ}$, Fig.11, shows similar trend as in previous two figures except that concentrations of fines with values of $50 \%$ and $75 \%$ are close to each other. From 
the previous we find that increasing inclination angle increases the pressure head loss for all combination of fines and coarse particles.

Figs.12, 13 and 14 show comparison between phosphate slurry with ratio of coarse to fine $1: 1$ at two different concentrations $(10 \%$ and $15 \%)$ for different inclination angles: zero, $20^{\circ}$ and $40^{\circ}$ respectively. From these figures we find that increasing the total solids concentration with fines addition decreases the pressure head loss for all angles of inclination. Also increasing the inclination angle increases the pressure head loss. This result can be explained due to the combination of presence of fines and increasing the concentration of coarse particles. The fine carrier decreases the settling behavior of coarse solids, thus reducing friction factor. Also coarse particles dampen the turbulence eddies resulting in lower pressure head loss.

Fig. 15 shows the effect of adding fines on pressure head loss at certain velocity for phosphate slurry of total concentration $10 \%$. From this figure it can be seen that increasing the flow velocity increases the pressure head loss. At low flow velocity (2 $\mathrm{m} / \mathrm{s}$ ) the addition of fines in the mixture has minor effect on pressure head loss. On the contrary at higher velocities ( 3 and $4 \mathrm{~m} / \mathrm{s}$ ) increasing the percentage of fines decreased the pressure head loss till fines concentration of $50 \%$ and then a peak occurred. For total solids concentration of $15 \%$ results obtained shown in Fig.16 gave opposite trends to that found in previous figure. At high velocity $(4 \mathrm{~m} / \mathrm{s})$ the addition of fine particles to the mixture has nearly no effect on pressure head loss. At lower velocities (2 and $3 \mathrm{~m} / \mathrm{s}$ ) adding fines increases slightly the pressure head loss till fines percentage of $25 \%$, further increase of fine particles shows a decrease in pressure head loss till a minimum at fines percentage of $50 \%$.

The effect of adding fines on the deposit velocity was also studied as the deposit velocity is an important parameter in design of slurry pipelines. Fig.17 shows the effect of adding fines on deposit velocity for different coarse/fine ratios for total mixture concentration $10 \%$. As a general trend increasing the angle of inclination increases the deposit velocity up to angle $30^{\circ}$, further increase of inclination angle decreases the deposit velocity. Adding fines with $33 \%$ in the total mixture increases the deposit velocity compared to coarse particles. Further increase of fines percentage decreases the deposit velocity compared to coarse particles up to inclination angle of $25^{\circ}$. Further increase of inclination angle increases the deposit velocity above that of coarse mixture. Coarse/fine ratio of 1:1 gave lower deposit velocity of the mixture than that of coarse slurry in the examined range of inclination angles. If the total solids concentration was raised to $15 \%$ the results of Fig. 17 change. Fig. 18 shows that the deposit velocity of the $50 \%$ fines ratio were nearly constant and compared to that of coarse particles at angles above $15^{\circ}$. The minimum mixture that gave lowest deposit velocity was that containing $75 \%$ fines.

From all previous results discussed we can conclude that adding fines to coarse slurry changes completely the behavior of the mixture regards pressure head loss and deposit velocity. This is due to the complex nature of the formed fluid due to presence of fines.

\section{CONCLUSIONS}

1. Increasing angle of inclination increases the pressure head loss for coarse and fines slurries.

2. Increasing the solids concentration (without adding fines) increases the pressure head loss 
3. Increasing the concentration with adding fines at ratio of $1: 1$ in the mixture decreases the pressure head loss.

4. The optimum flow velocity for fines addition to be efficient is around $3 \mathrm{~m} / \mathrm{s}$ regardless to the total mixture concentration.

5. The deposit velocity is affected by solids concentration and the presence of fines.

6. No design correlations were found due to the wide range of coarse/fines ratios used. Thus further work should be carried out in a narrow range of fines addition $\approx 20-50 \%$ at velocities around $3 \mathrm{~m} / \mathrm{s}$.

\section{ACKNOWLEDGEMENT}

The authors would like to express their deep gratitude to students of slurry transport project through the years 2002-2005 for carrying out the experiments of this work as part of their B.Sc. graduation project.

\section{REFERENCES}

1. Charles, M.E. and Charles, R.A. The use of heavy media in the pipeline transport of particulate solids. In Advances in solid-liquid flow in pipes and its applications. Zandi, I. (editor), Pergamon press, oxford, pp. 187-197,(1971),

2. Kenchington, J.M. Prediction of critical conditions for pipeline flow of settling particles in heavy medium. 4th international conference on the hydraulic transport of solid in pipes, BHRA, Cranfield, U.K. (1976).

3. Duckworth, R.A., Pullum, L., Addie, G.R. and Lockyear, C.F. The pipeline transport of coarse materials in a non-Newtonian carrier fluid. 10th international conference on the hydraulic transport of solids in pipes, 29-31 Oct. Innsbruck, Austria. (1986).

4. Duckworth, R.A., Addie, G.R. and Maffet, J.R. Mine waste disposal by pipeline using a fine slurry carrier. 11th international conference on slurry technology, Washington D.C., U.S.A. (1986).

5. Duckworth, R.A. and Addie, G.R. Application of a non-newtonian carrier to transport coarse coal refuse. 12th international conference on slurry technology.. Washington D.C., U.S.A. (1987)

6. Hou, H.C. Investigation of optimal grain distribution for transport with high concentration. Hydrotransport 10. BHRA. Cranfield UK, pp 178-183, (1986)

7. Sellegren, A. and Addie, G. Cost-effective pumping of coarse mineral products using fine sands. Powder Technology, 94, pp. 191-194. (1997).

8. Fangary, Y.S, Abdel-Ghani, A.S., El Haggar, S.M. and Williams, R.A. The effect of fine particles on slurry transport processes. Minerals Engineering, Vol. 10, No. 4, pp. 427-439. (1997).

9. Ghanta, K.C. and Purohit, N.K. Pressure drop prediction in hydraulic transport of bi-dispersed particles of coal and copper ore in pipeline. The Canadian Journal of Chemical Engineering, Vol.77, pp. 127-131. (1999).

10. Kawashima, T. and Noda, K. Hydraulic transport of solids in an inclined pipe: Theoretical and experimental studies on pressure loss. 1st international conference on the hydraulic transport of solid in pipes, University of Warwick, U.K. 1-4 Sept., (1970). 
11. Hashimoto, H., Noda, K., Masuyama, T. and Kawashima, T. Influence of pipe inclination on deposit velocity. 7th international coneference on the hydraulic transport of solids in pipes, Sendai, Japan. 4-6 Nov., (1980)

12. Wilson, K.C. and Tse, J.K.P. Deposition limit for coarse-particle transport in inclined pipes. 9th international conference on the hydraulic transport of solids in pipes, Rome, Italy. 17-19 Oct., (1984). 


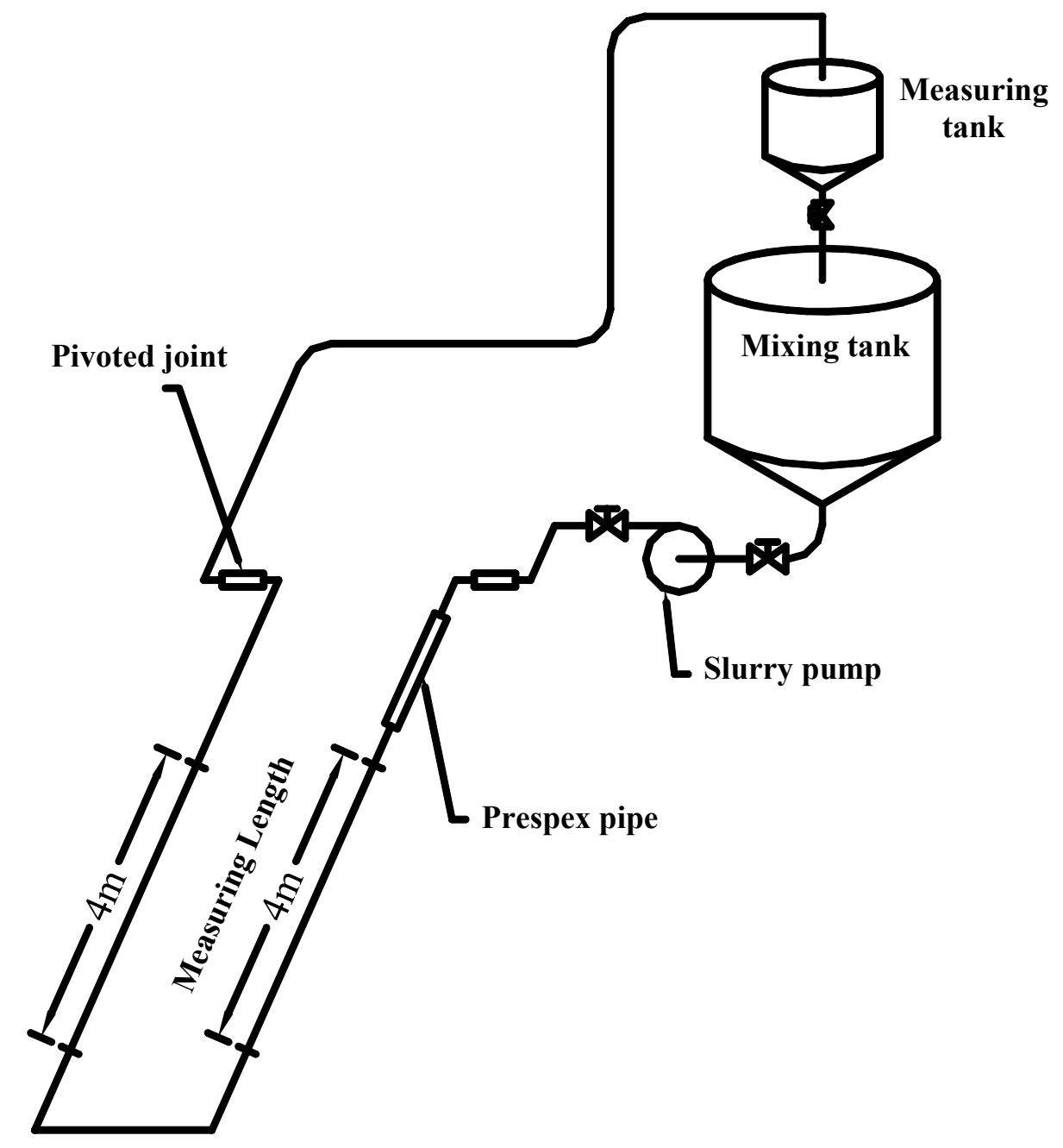

Fig.1 Experimental test rig. 




Fig.(2) Effect of inclination angle in degrees on pressure head loss for phosphate water slurry

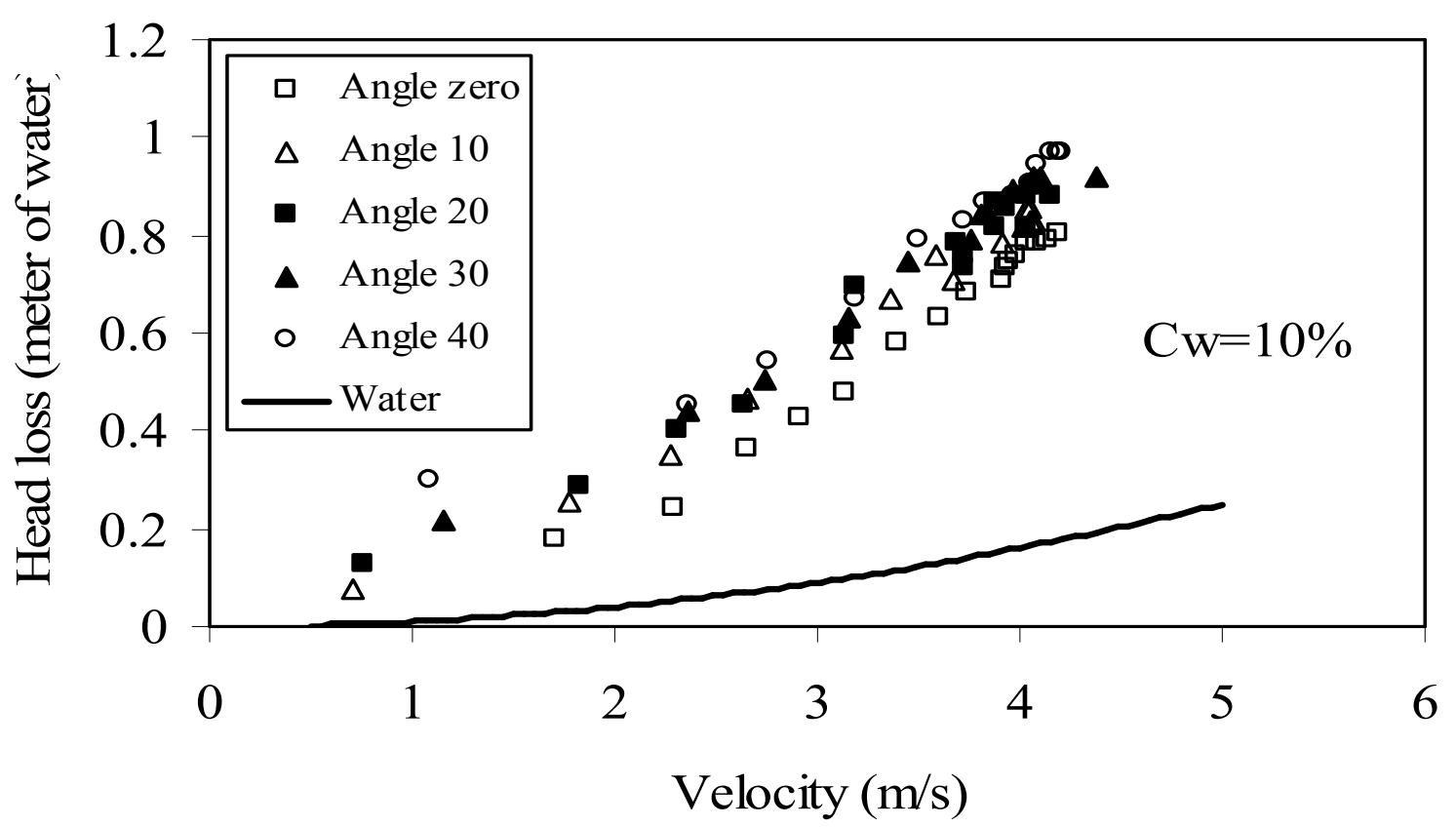

Fig.(3) Effect of inclination angle (in degrees) on pressure head loss of fine phosphate water slurry 


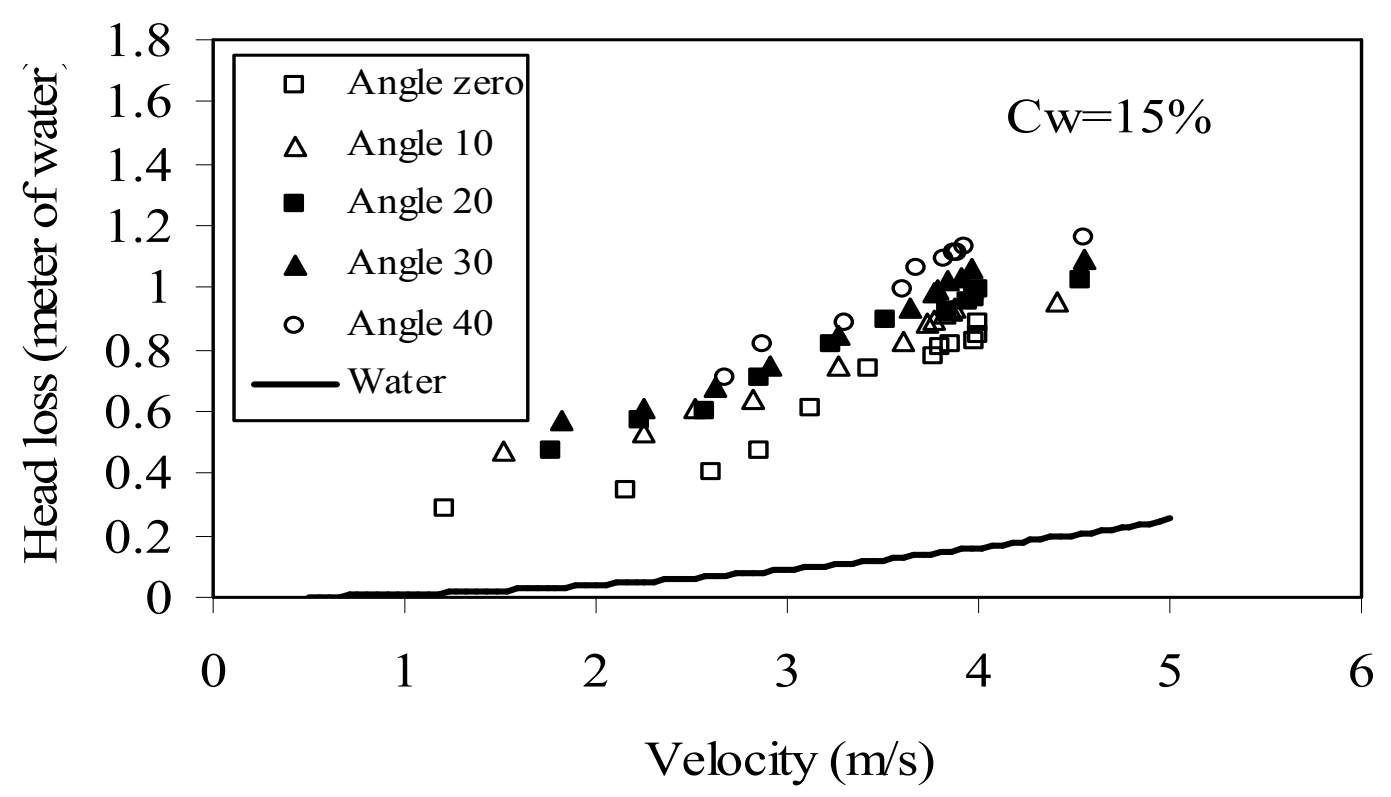

Fig. (4) Effect of inclination angle in degrees on pressure head loss for phosphate water slurry.

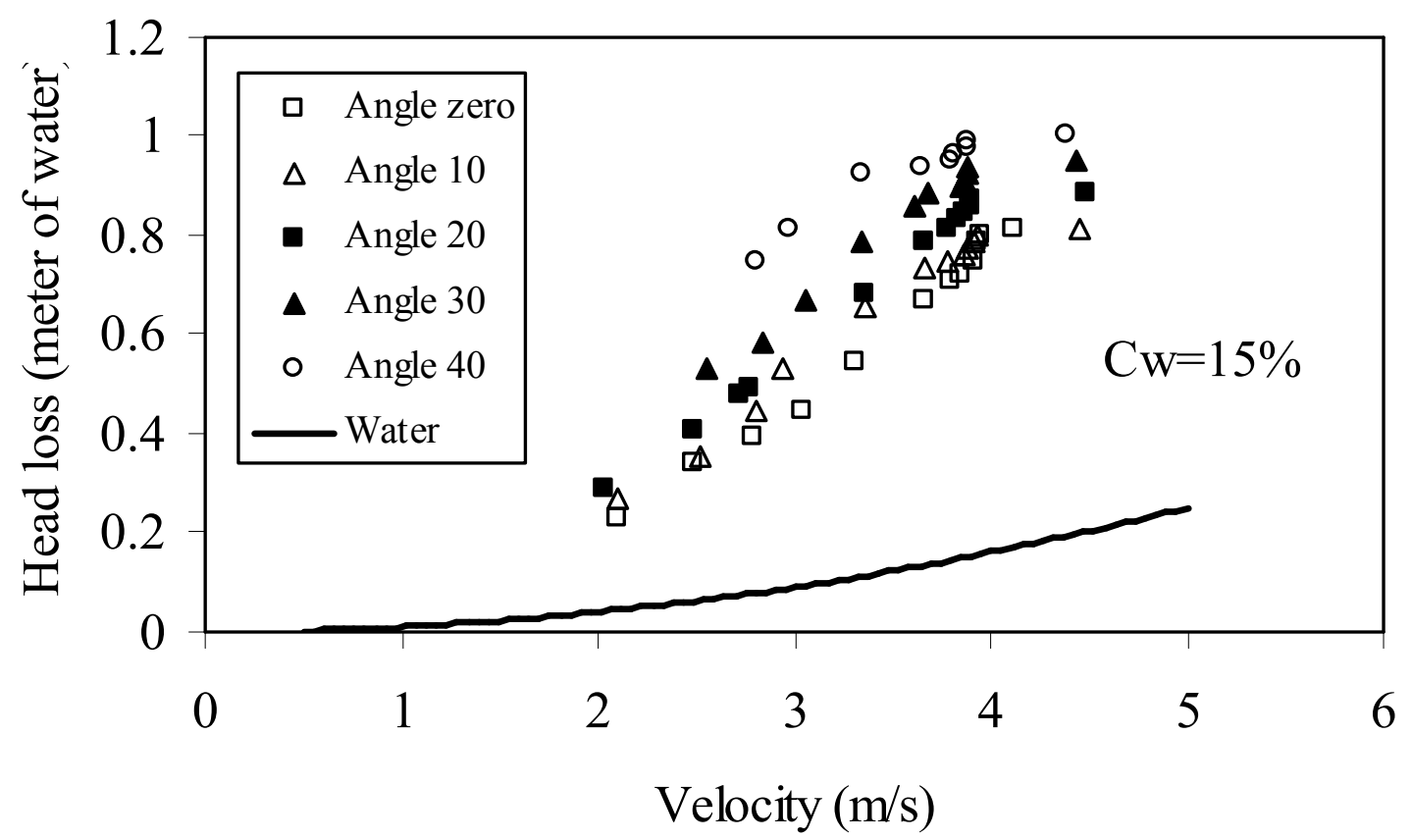

Fig.(5) Effect of inclination angle in degrees on pressure head loss of fine phosphate water slurry 


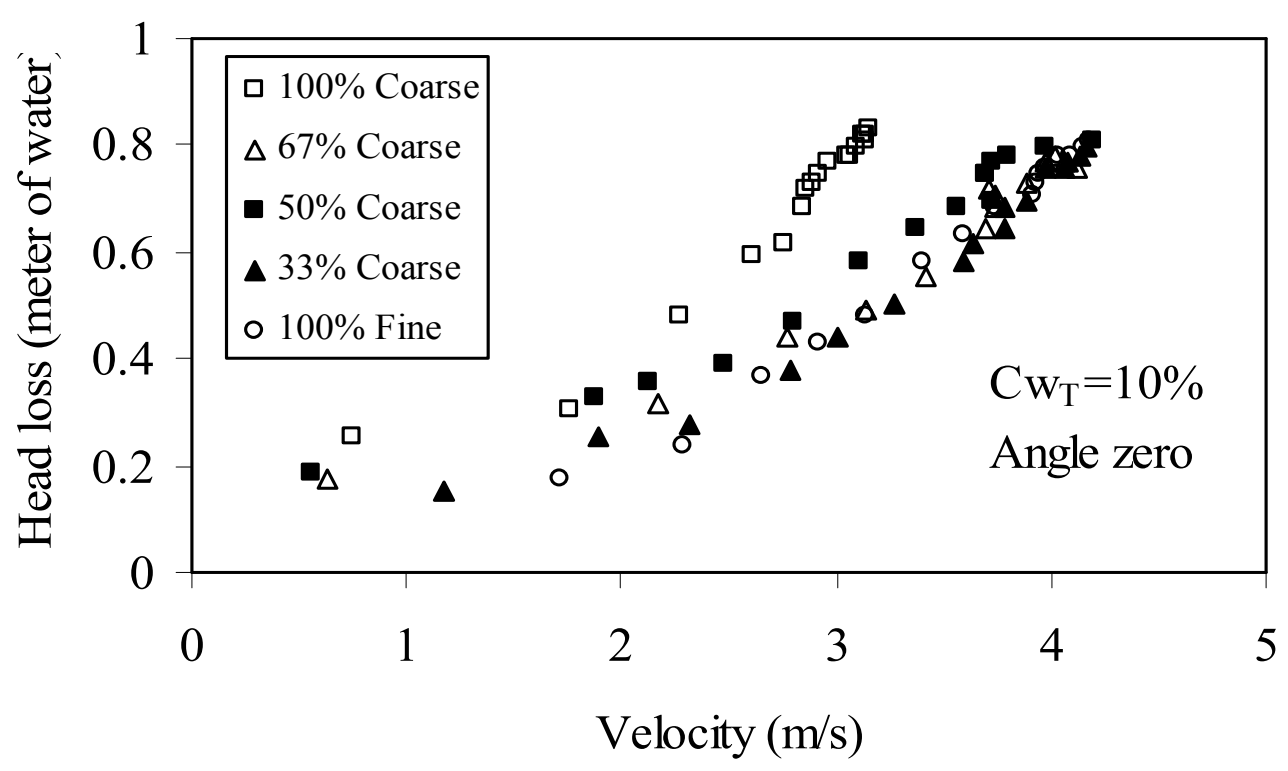

Fig.(6) Effect of adding fine particles on pressure head loss of phospate water slurry

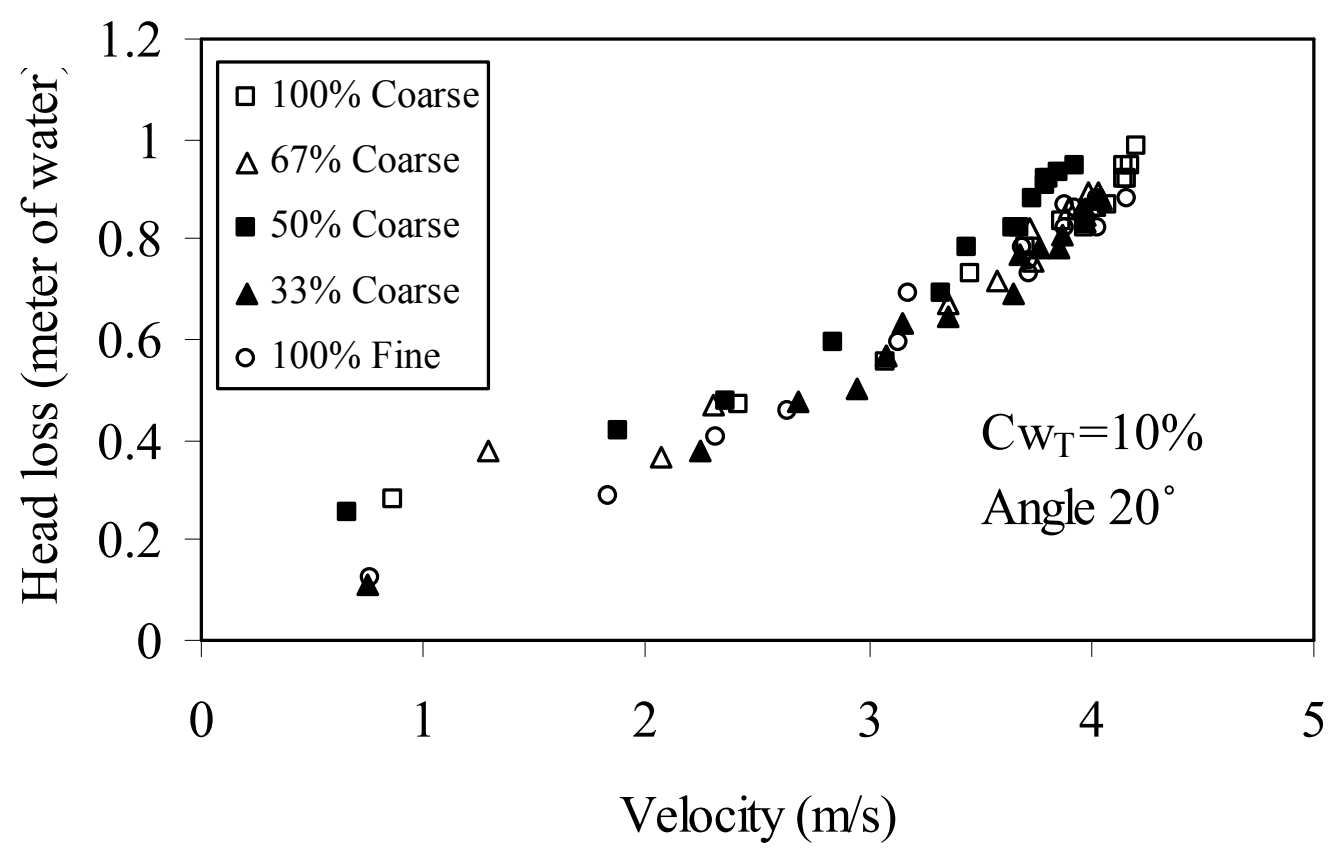

Fig.(7) Effect of adding fine particles on pressure head loss of phosphate water slurry 


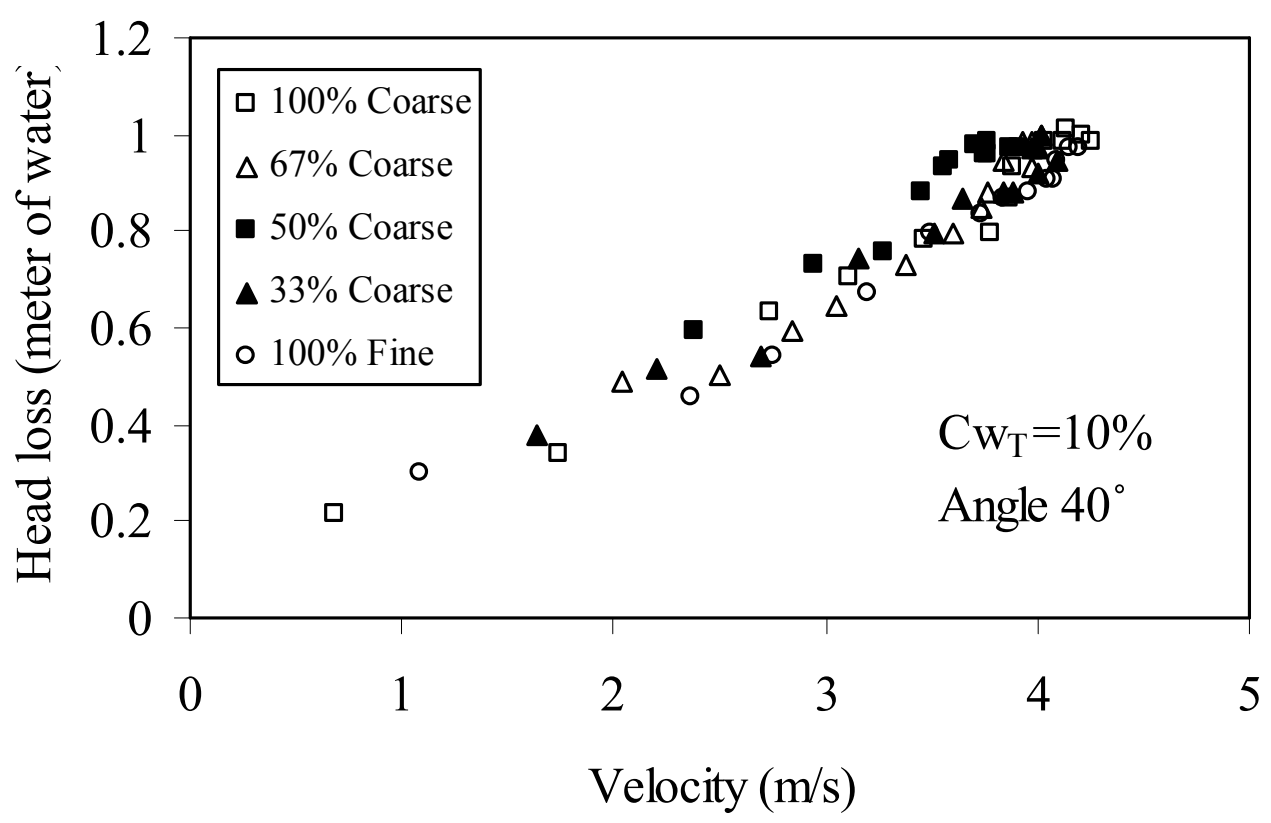

Fig.(8) Effect of adding fine particles on pressure head loss of phosphate water slurry

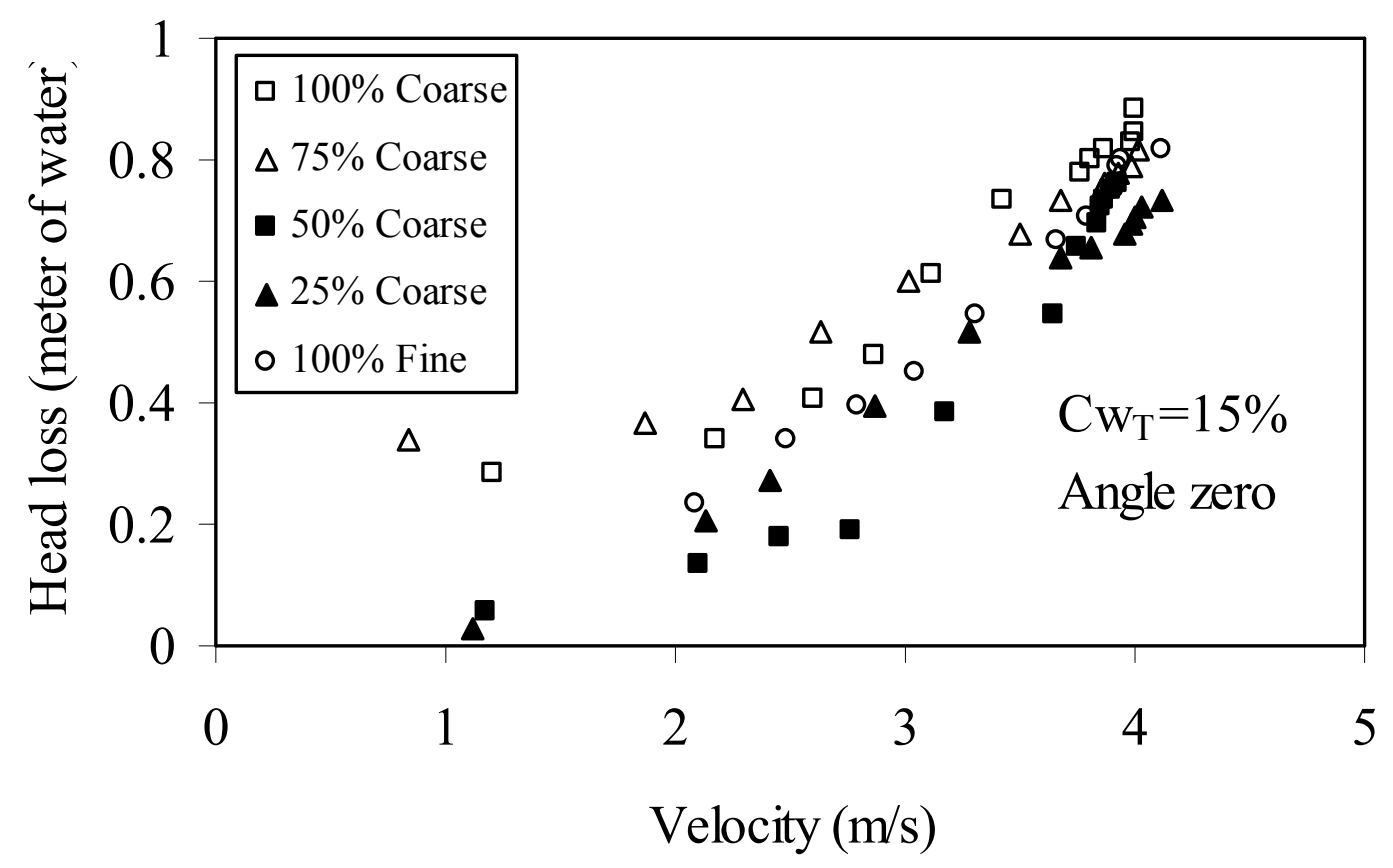

Fig.(9) Effect of adding fine particles on pressure head loss of phosphate water slurry. 


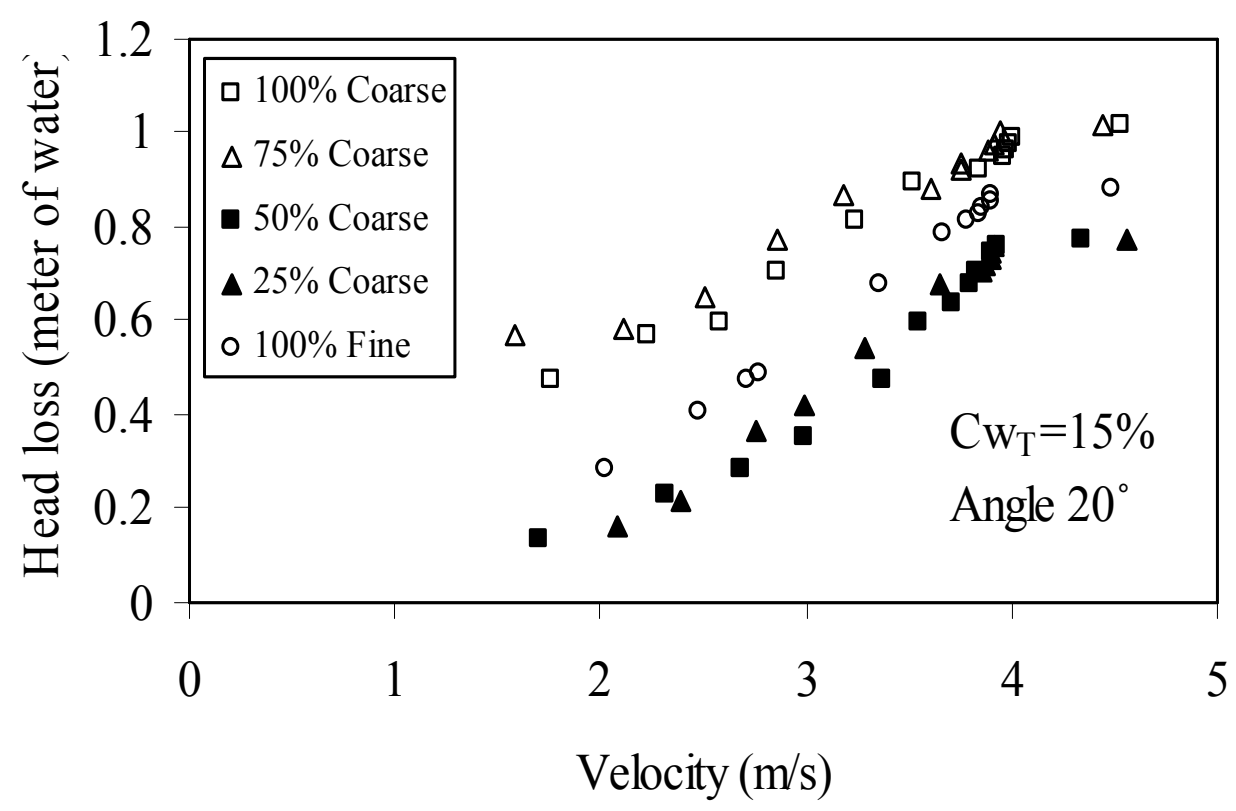

Fig.(10) Effect of adding fine particles on pressure head loss of phosphate water slurry

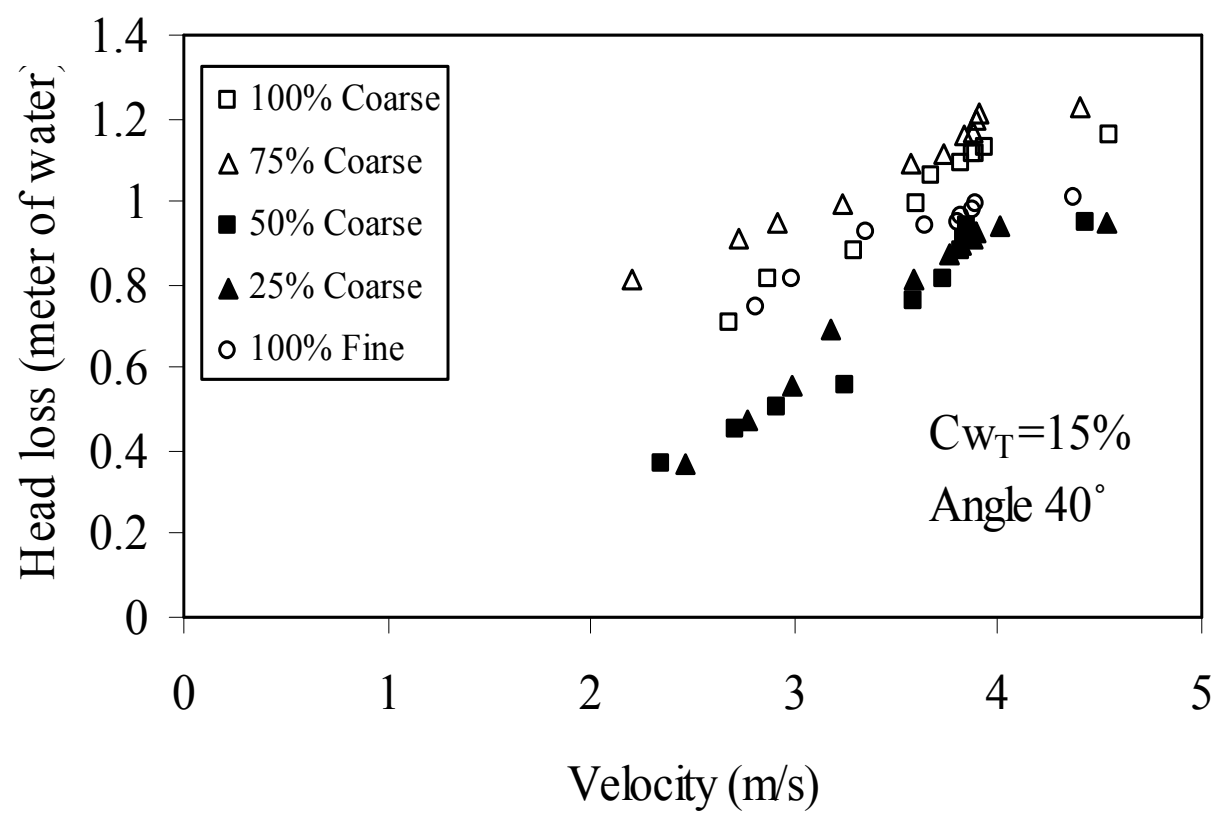

Fig.(11) Effect of adding fine particles on pressure head loss of phosphate water slurry 


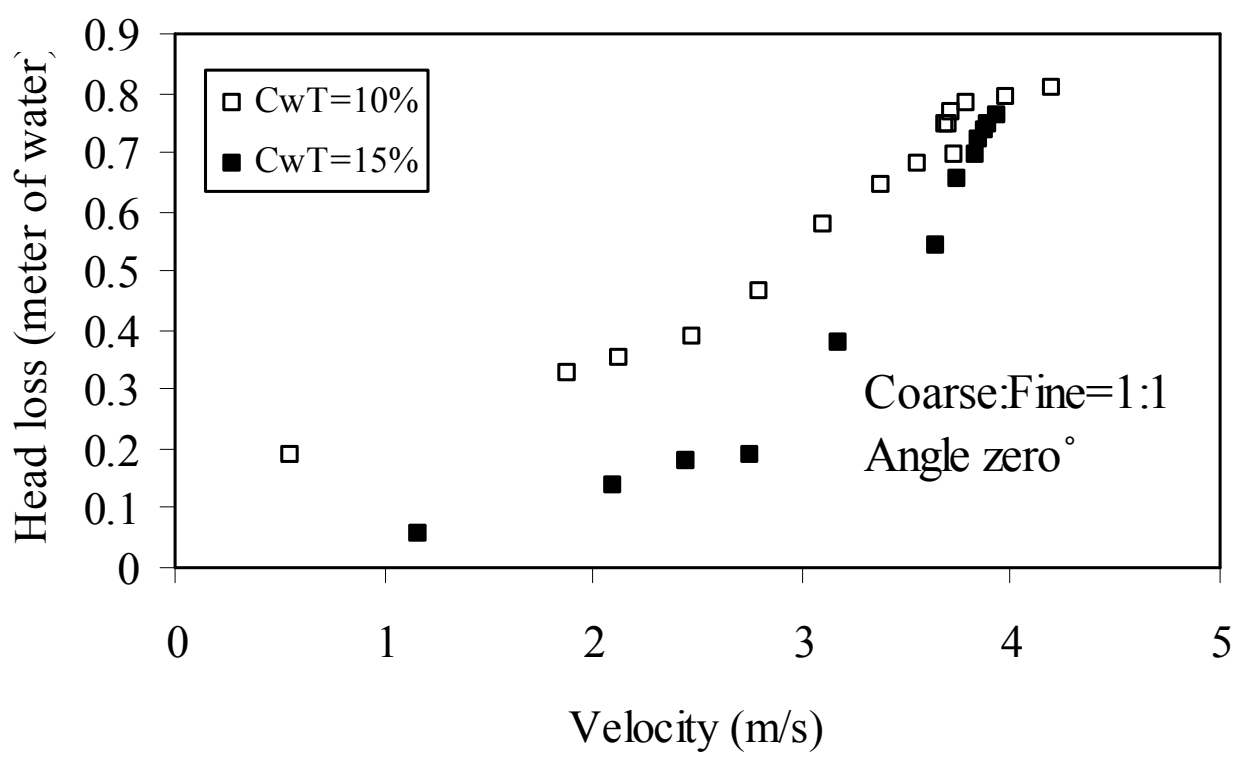

Fig.(12 Effect of adding fine particles on pressure head loss of phosphate water slurry for different concentrations

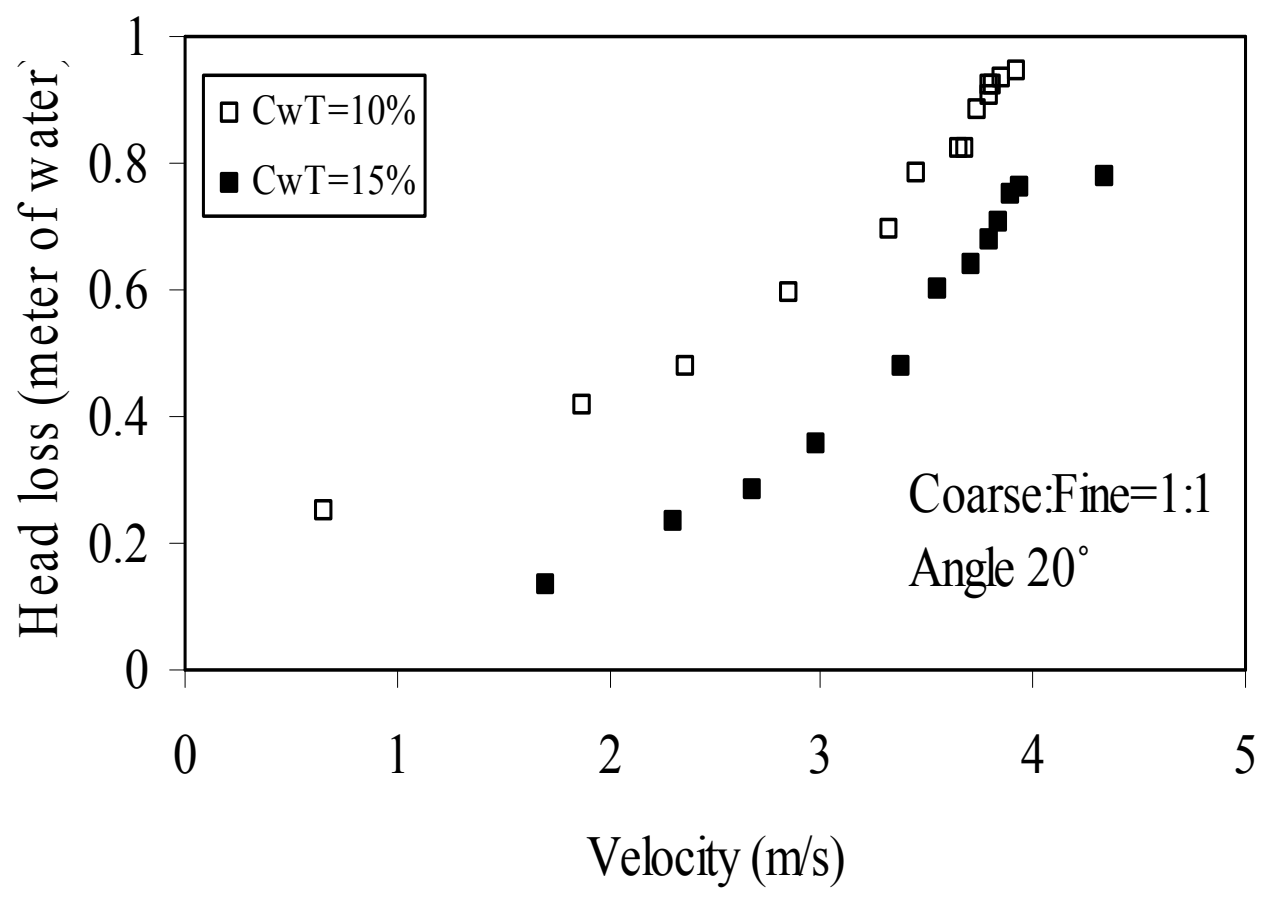

Fig.(13) Effect of adding fine particles on phosphate water slurry for different concentrations 


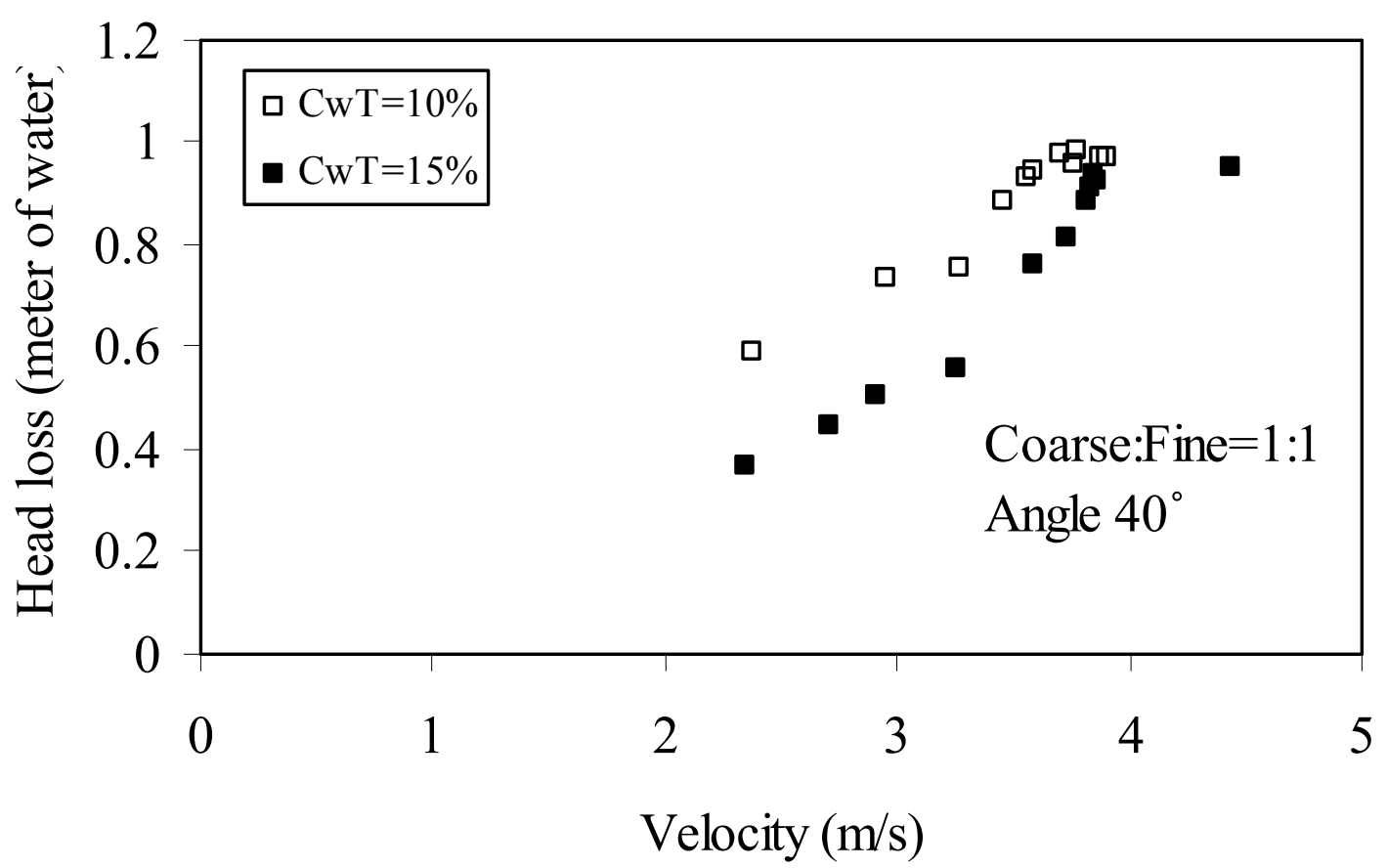

Fig.(14) Effect of adding fine particles on pressure head loss of phosphate water slurry for different concentrations

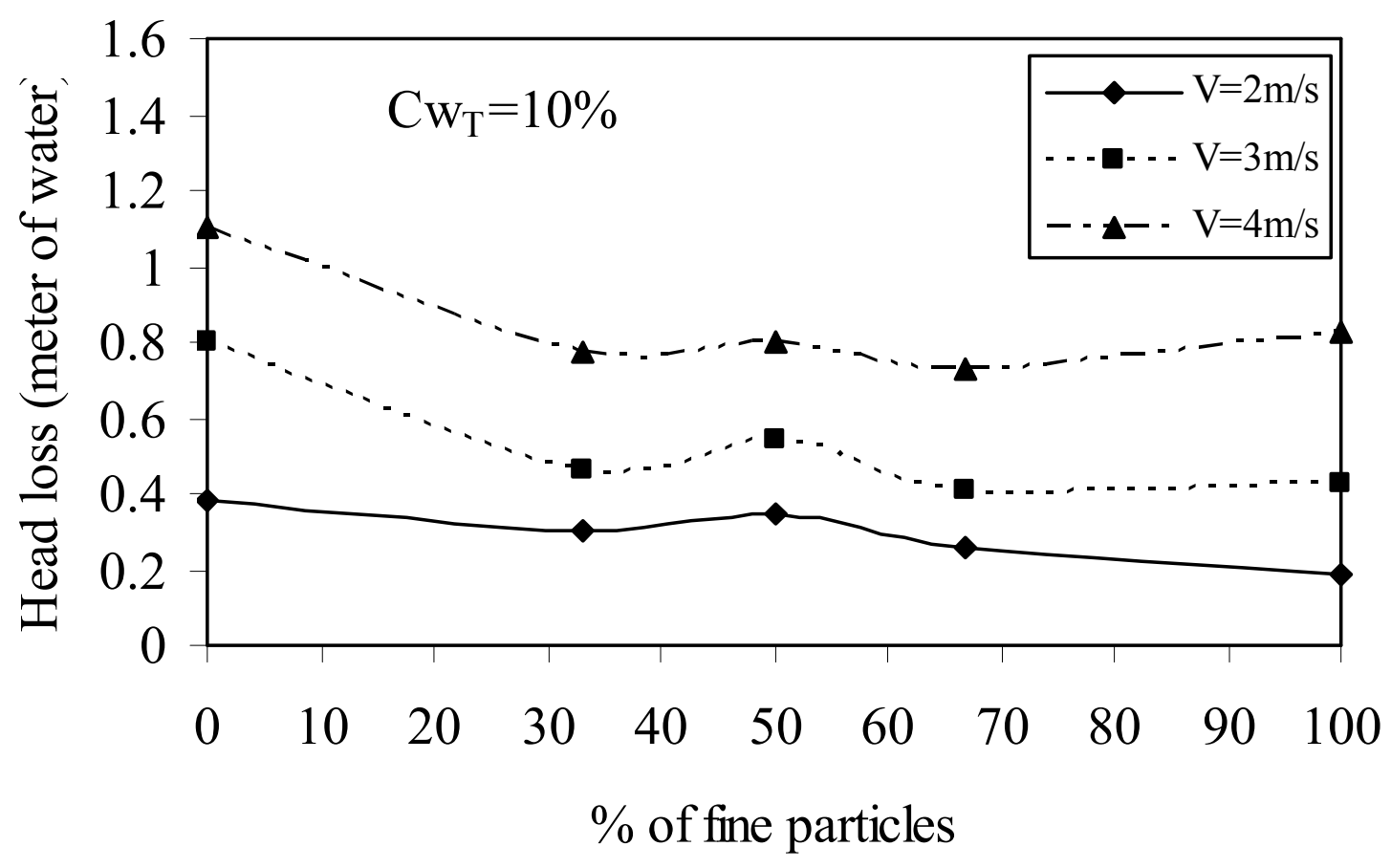

Fig.(15) Effect of adding fine particles on pressure head loss for phosphate water slurry at certain velocity 




Fig.(16) Effect of adding fine particles on pressure head loss for phosphate water slurry at certain velocity

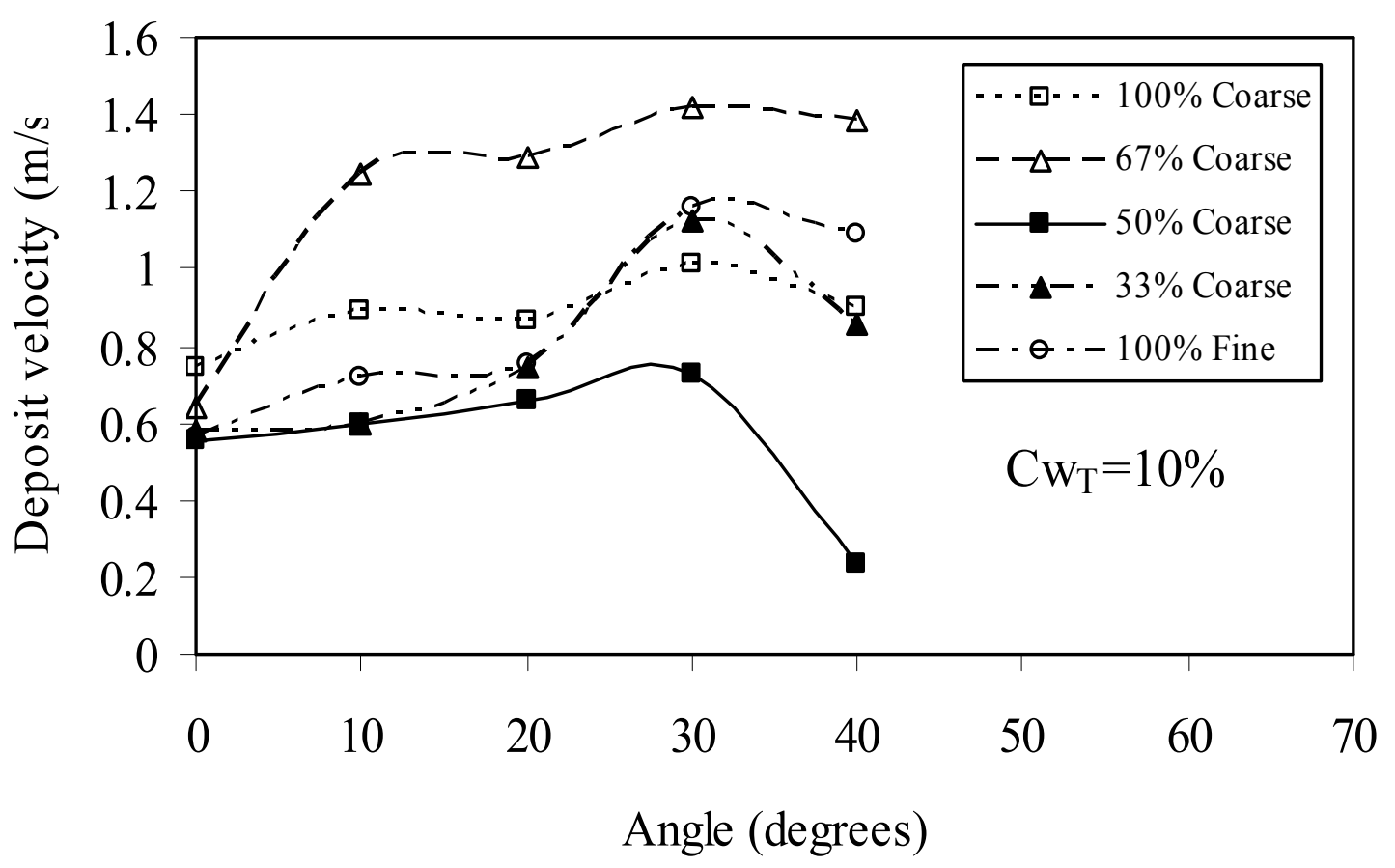

Fig.(17) Effect of adding fine particles on deposit velocity at different inclination angles 


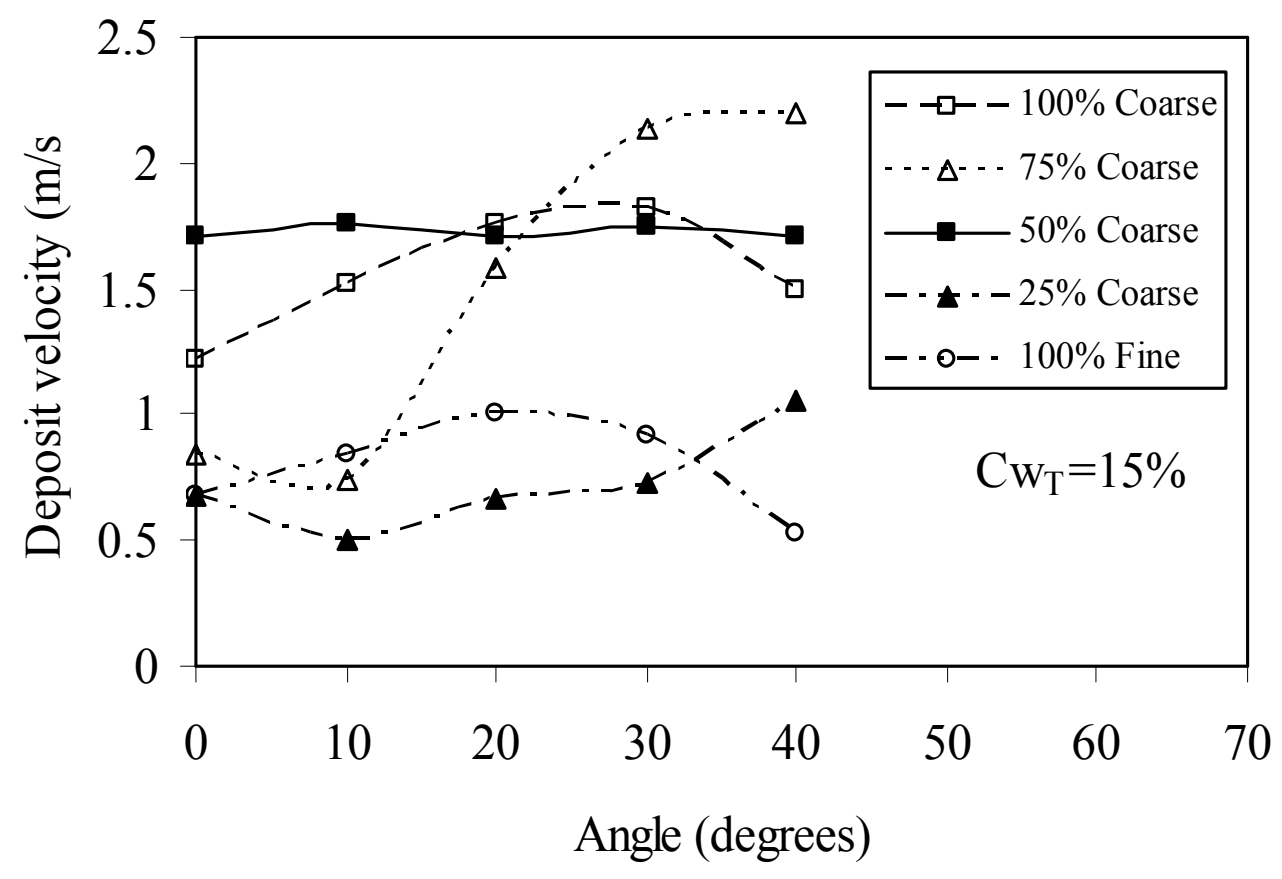

Fig.(18) Effect of adding fine particles on deposit velocity at different inclination angles 